\title{
Automatic Controlling Of Train Using Wireless Protocol Zigbee
}

\author{
Omkar Khare ${ }^{1,}$ Guide: Dr.P.B.Mane ${ }^{2}$ \\ ${ }^{1}$ (Electronics and Telecommunication Engineering, All India Shree Shivaji Memorial Society's Institute of \\ Information Technology/Pune University, India) \\ ${ }^{2}$ (Principal, All India Shree Shivaji Memorial Society's Institute of Information Technology/Pune University, \\ India)
}

\begin{abstract}
In INDIA railways is one of the important means of transport. Driver of the train has to look out to get the status of the signal, if he fails to see the signal major mishaps could take place. There are different systems in use today including AWS (auxilliary warning system), ACD (automatic collision detection). AWS system is in use by western railway while ACD is used by Konkan railway.AWS system has a drawback of theft of trackside equipment while ACD system is based on GPS system where satellite is US owned. Proposed system focusses on automation of train controlling to avoid accidents. Designed system involves transfer of the status of signal directly to the engine which will control speed of the train as per the status of the signal. System has been designed to provide safe travelling especially during bad weather. System is based on wireless protocol 'Zigbee'. Low power consumption, low latency time of $30 \mathrm{~ms}$ and excellent security features as Zigbee uses 128AES, use of DSSS modulation technique in Zigbee makes this system reliable and safe. System is operating within a range of $120 \mathrm{~m}$
\end{abstract}

Keywords - Zigbee, ACD, AWS, PIC Microcontroller,

\section{INTRODUCTION}

Railway has become the important means of transport today. For extensive railway network in India an efficient management system is required to avoid train accidents. Current safety system is appreciable yet owing to the motorman negligence or bad atmospheric conditions can lead to the unavoidable accidents, so there is a need to develop a system which will decrease margin of error of the current system and thereby making it safer. There are several issues regarding safety of train including terrain issues, atmospheric issues, obstruction, or there may be human negligence or there may be motorman mishap. Train has to travel through dense forests, hilly region where visibility becomes a major issue and signal may be misinterpreted, visibility is further reduced during foggy or stormy weather, Motorman has to take quick decisions so it is possible that he may make an error, if anything happens to the motorman's health it puts all the passengers in the train to the risk. So there is a need to design a system which will overcome all these issues and provides secure travelling. Current systems includes AWS (Auxilliary warning system), ACD (Automatic collision detection) [a] [3]. In case of AWS warning is given to the driver in advance regarding status of the signal and driver has to take appropriate action within stipulated time, but there is a possibility of ignorance of the warning by the driver, in case of ACD GPS satellite is US owned[b] [1] so there is a possibility of withdrawing of service during war conditions. Taking into account shortcomings of these systems, implemented system works solely on wireless protocol zigbee which is the emerging wireless technology and provides security and reliability

Designed system involves transmitting the status of the signal to the engine so that it will take appropriate action, based on the status of the signal engine will adjust its speed and eliminates human intervention in controlling of the train. Security features are excellent compared to GSM since encryption is used. Government is trying its best to tackle situation by incorporating various new technologies, some of which is TPWS (Train protection and warning system) which is currently in use in europian countries .Main aim of this system is to minimize trains of breaching signals and act as a deterrent for speeding trains [b] [2], Kolkata metro corporation is planning to opt this system in next year [b] [3], but the cost factor has become the critical issue in this system. Designed system satisfies both the security, reliability factors as well as cost effective. Very low power consumption, low latency time, less interference makes proposed system effective.

\section{Introduction}

\section{ZIGBEE TECHNOLOGY}

ZigBee, the name of a specification for a suite of high level communication protocols using small, low power digital radios based on the IEEE 802.15.4-2006 standard for wireless personal area networks (WPANs), The technology is intended to be simpler and less expensive than other WPANs, such as Bluetooth. ZigBee is targeted at radio-frequency (RF) applications that require a low data rate, long battery life, and secure networking. ZigBee is a low-cost, low-power, wireless mesh networking standard. The low cost allows the 
technology to be widely deployed in wireless control and monitoring applications, the low power-usage allows longer life with smaller batteries, and the mesh networking provides high reliability and larger range. The ZigBee Alliance, the standards body which defines ZigBee. ZigBee operates in the industrial, scientific and medical (ISM) radio bands; $868 \mathrm{MHz}$ in Europe, $915 \mathrm{MHz}$ in countries such as USA and Australia, and $2.4 \mathrm{GHz}$ ISM band in most jurisdictions worldwide. Compared to existing wireless protocols like bluetooth, Wi-fi zigbee is more advantageous as we can get range upto $1.6 \mathrm{~km}$. Zigbee is more cost effective and has low power consumption, has excellent security features as encryption is used [a] [1]. Different topologies can be implemented with zigbee protocol including mesh topology, peer to peer.

\subsection{Protocols}

The current profiles derived from the ZigBee protocols support beacon and non-beacon enabled networks. In non-beacon-enabled networks, an unslotted CSMA/CA access mechanism is used. In this type of network, ZigBee Routers typically have their receivers continuously active, requiring a more robust power supply. However, this allows for heterogeneous networks in which some devices receive continuously, while others only transmit when an external stimulus is detected. In beacon-enabled networks, the special network nodes called ZigBee Routers transmit periodic beacons to confirm their presence to other network nodes. Nodes may sleep between beacons, thus lowering their duty cycle and extending their battery life.

1.2 Important Characteristics of Zigbee

a) Low power consumption-1 $\mathrm{mW}[\mathrm{a}][1]$

b) Long Battery life

c) High density of nodes per network

d) High Throughput

e) Low interference

f) DSSS modulation technique

g) 128-AES encryption is used

h) Low latency time of $30 \mathrm{~ms}$

III. FIGURES AND TABLES

\section{BLOCK DIAGRAM OF SYSTEM}

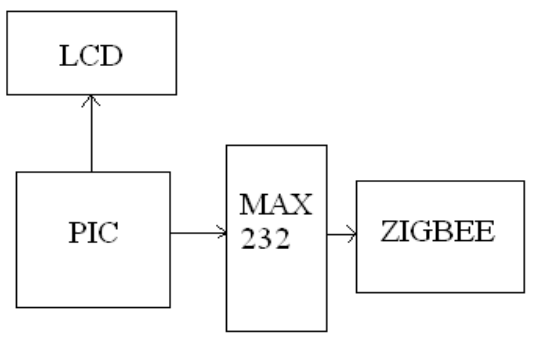

Fig: Transmitter section

Above diagram shows transmitter diagram where zigbee module, PIC microcontroller and MAX 232 are required. MAX 232 is required to matcch voltage levels of zigbee and PIC.

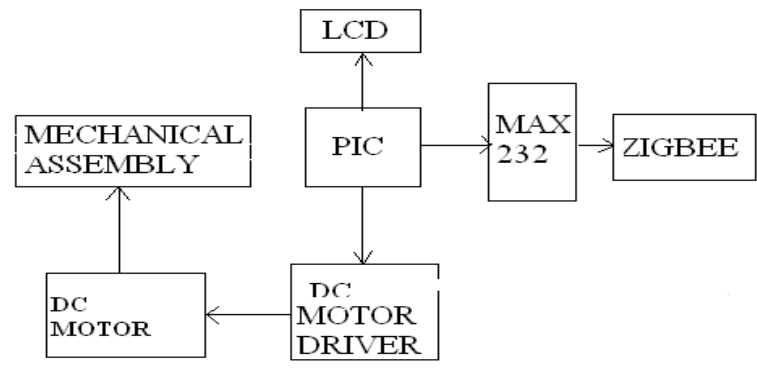

Fig: Receiver section Operation of the system 


\begin{tabular}{|c|c|c|}
\hline $\begin{array}{c}\text { Sr. } \\
\text { No }\end{array}$ & Signal status & Action taken by engine \\
\hline 1 & GREEN & Maintain the speed \\
\hline 2 & YELLOW & Reduce the speed \\
\hline 3 & RED & Stop \\
\hline
\end{tabular}

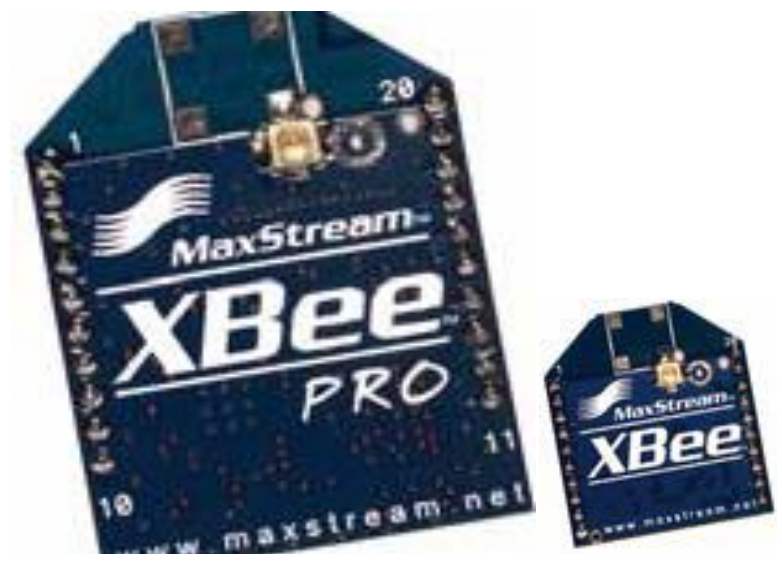

Fig: Zigbee Module

\section{CONCLUSION}

Implemented system works satisfactorily during bad weather especially foggy weather where driver may fail to see the signal properly. Low power consumption of zigbee of $1 \mathrm{~mW}$ and secure and reliable communication makes this system a good choice to implement. We can have better performance if we use zigbee pro which is having a range of $1.6 \mathrm{~km}$. Proposed system is best alternative to the traditional methods including route relay interlocking and computer based interlocking. Low latency time of zigbee has proved to be a very good feature. ACD (automatic collision detection) is totally based on GPS system which is being governed by American government while TPWS will cost around Rs 70,000 per km [b] [1]. Compared to this systems designed system can provide a good alternative due to the moderate cost. We can extend this concept using wireless protocol WIMAX which has a very good range and data rate and security features are also good [a] [2].

\section{Journal Papers:}

\section{REFERENCES}

[1] Zigbee Alliance, "White paper on Zigbee technology", June 2007

[2] Jin- Shyan lee, Yu-Wei su,Chung-chou shen " "Comparative study of Wireless Protocols- Bluetooth,Wi- Fi,UWB,Zigbee", 33 ${ }^{\text {rd }}$ annual conference of IEEE Industrial Electronics Society(IECON)-Nov 5-8 2007,Taiwan

[3] Bhavneet Sidhu, Hardeep Singh, Amit Chhabra, "Emerging Wireless Standards- Wifi, Zigbee, WiMAX", World academy of science, engineering and Technology Nov 25, 2007

[4] Patrick Kinny, "Zigbee Technology- Wireless control that simply works”, Communication design conference, October 2,2003

\section{Websites}

[1] IRSSE- Indian Railway Services of Signal Engineers

[2] Indianrlys.wordpress.com

[3] KMRC- Kolkata Metro Rail Corporation

\section{Reports}

[1] Report of high level safety review committee, Feb 2012, under the chairmanship of Mr. Anil kakodkar 